\title{
BIBLIOGRAPHY
}

1. L. Carleson, On a class of meromorphic functions and its associated exceptional sets, Thesis, University of Uppsala, 1950.

2. O. Frostman, Potentiel d'équilibre et capacité des ensembles avec quelques applications d la theorie des fonctions, Medd. Lunds Univ. Mat. Sem. vol. 3 (1935) pp. 1118.

3. - Sur les produits de Blaschke, Kungliga Fysiografiska Sällskapet i Lund förhandlingar vol. 12 (1942) pp. 169-182.

Lincoln Laboratory, Massachusetts Institute of Technology

\section{ON BOUNDED FUNCTIONS WITH ALMOST PERIODIC DIFFERENCES}

\section{RAOUF DOSS}

The aim of this paper is to generalize to groups the well-known Bohl-Bohr theorem, which states that if the indefinite integral, $F(x)$ $=\int_{a}^{x} f(t) d t$, of an almost periodic function $f(x)$, is bounded, then it is almost periodic (see [1] or [2]).

No expression of the form $\int_{0}^{x} f(t) d t$ is available in groups, but observing that $F(a+x)-F(x)=\int_{x}^{x+a} f(t) d t$ is easily proved to be almost periodic, whatever be the constant $a$, we are led to the following

THEOREM. Let $G$ be a multiplicative group and let the left differences $F(a x)-F(x)$ be right almost periodic for every $a \in G$, where $F$ is a given complex-valued function on $G$. If $F(x)$ is bounded then it is right almost periodic.

We recall that a real or complex function $\phi(x)$ is right almost periodic if, from every sequence $\left(c_{n}\right)$ we can extract a subsequence $\left(b_{n}\right)$ for which the functions $\phi\left(x b_{n}\right)$ converge uniformly in $G$. In that case to every $\epsilon>0$ there corresponds a finite number of elements of $G$, say $s_{1}, \cdots, s_{k}$, such that to every $t \in G$ we can associate an integer $i \leqq k$ for which

$$
\left|\phi(x t)-\phi\left(x s_{i}\right)\right|<\epsilon, \quad \text { whatever bel } x \in \mathbb{R} G .
$$

Proof of THE THEOREM. It is sufficient to consider the case of a real function. Suppose that $F(x)$ is not right almost periodic. Then there exists an $\alpha>0$ and a sequence $\left(c_{n}\right)$, such that, in every subse-

Received by the editors June 30, 1960. 
quence $\left(b_{n}\right) \subset\left(c_{n}\right)$ we can find $b_{p}, b_{q}$ for which sup $\left|F\left(x b_{p}\right)-F\left(x b_{q}\right)\right|$ $>\alpha$. We can even suppress the modulus sign by exchanging if necessary $b_{p}$ and $b_{q}$. In other words there exist $t \in G, b_{p}, b_{q}$ such that

$$
F\left(t b_{q}^{-1} b_{p}\right)-F(t)>\alpha .
$$

We shall prove that if $F\left(a_{1} x_{1}\right)-F\left(x_{1}\right)>\beta$, we can find $x_{2}, a_{2} \in G$ such that $F\left(a_{2} x_{2}\right)-F\left(x_{2}\right)>\beta+\alpha$. This will show that $F(x)$ is unbounded, against the hypothesis, and the theorem will be proved.

So put $\phi(x)=F\left(a_{1} x\right)-F(x)$ and suppose that

$$
\phi\left(x_{1}\right)=\beta+\epsilon>\beta \text {. }
$$

Since $\phi(x)$ is right almost periodic let $s_{1}, \cdots, s_{k}$ be such that to every $t \in G$ we can associate an integer $i \leqq k$ for which $\left|\phi(x t)-\phi\left(x s_{i}\right)\right|<\epsilon / 2$. In particular, for $x=x_{1} s_{i}^{-1}:\left|\phi\left(x_{1} s_{i}^{-1} t\right)-\phi\left(x_{1}\right)\right|<\epsilon / 2$, so that by (2) $\phi\left(x_{1} s_{i}^{-1} t\right)>\beta+\epsilon / 2$, i.e.,

$$
F\left(a_{1} x_{1} s_{i}^{-1} t\right)-F\left(x_{1} s_{i}^{-1} t\right)>\beta+\epsilon / 2 .
$$

Now consider the right almost periodic functions

$$
\phi_{i}(x)=F\left(a_{1} x_{1} s_{i}^{-1} x\right)-F(x) \quad(i=1, \cdots, k) .
$$

We can extract from the sequence $\left(c_{n}\right)$ a subsequence $\left(b_{n}\right)$ such that $\left|\phi_{i}\left(x b_{q}^{-1} b_{p}\right)-\phi_{i}(x)\right|<\epsilon / 2$, whatever be $x \in G, b_{p}, b_{q}$, and $i=1, \cdots, k$. We deduce

$$
\begin{array}{r}
\left|F\left(a_{1} x_{1} s_{i}^{-1} t b_{q}^{-1} b_{p}\right)-F\left(t b_{q}^{-1} b_{p}\right)-F\left(a_{1} x_{1} s_{i}^{-1} t\right)+F(t)\right| \\
=\left|\phi_{i}\left(t b_{q}^{-1} b_{p}\right)-\phi_{i}(t)\right|<\epsilon / 2 .
\end{array}
$$

Hence by (1)

$$
F\left(a_{1} x_{1} s_{i}^{-1} t b_{q}^{-1} b_{p}\right)-F\left(a_{1} x_{1} s_{i}^{-1} t\right)>\alpha-\epsilon / 2 .
$$

(3) and (4) give, by addition, the required relation:

$$
F\left(a_{1} x_{1} s_{i}^{-1} t b_{q}^{-1} b_{p}\right)-F\left(x_{1} s_{i}^{-1} t\right)>\alpha+\beta .
$$

The proof is now complete.

\section{REFERENCES}

1. H. Bohr, Fastperiodische Funktionen, Berlin, Springer, 1932.

2. J. Favard, Leçons sur les fonctions presque periodiques, Paris, Gauthier-Villars, 1933.

Cairo University, Egypt, U.A.R. 